\title{
Ranking of petrochemical companies using preferential voting at unequal levels of voting power through data envelopment analysis
}

\author{
Hamid Sharafi ${ }^{1}$. Farhad Hosseinzadeh Lotfi ${ }^{1}$ (1) . Gholamreza Jahanshahloo ${ }^{1}$. Mohsen Rostamy-malkhalifeh ${ }^{1}$. \\ Mehdi Soltanifar ${ }^{2} \cdot$ Somayeh Razipour-GhalehJough ${ }^{1}$
}

Received: 11 July 2018 / Accepted: 26 August 2019 / Published online: 6 September 2019

(c) The Author(s) 2019

\begin{abstract}
The initial issue that must be addressed in teamwork is the manner in which decisions are made by the group and its members. Voting is a procedure to aggregate individual votes to achieve a collective decision. Since individuals have varied opinions and preferences, preferential voting assists in conveying the priorities of the voters to the society or community. In many circumstances, such as voting-based managerial decisions, voters are of a voting preference of unequal voting power. This paper presents a method for the ranking of preferential voting with voters of unequal voting power, which, in addition to the utilization of preference voting models, employs the DEA and assurance region techniques. The deployment of DEA technique causes an increment in the competence of discriminating the ranking of candidates, and in the finale the proposed method is expressed for an empirical example to rank the petrochemical companies in the Tehran Stock Exchange.
\end{abstract}

Keywords Preferential voting $\cdot$ Data envelopment analysis (DEA) $\cdot$ Voters of unequal voting power $\cdot$ Stock exchange

\section{Introduction}

Cook and Kress [1] employed the constraints of the assurance region which was introduced by Thompson [2,3] and, by utilizing the model of Charnes et al. [4], introduced a model for ranking, which seeks the desirable weight vector for each candidate. The model presented by Cook and Kress [1] has two main problems. The preliminary difficulty

Farhad Hosseinzadeh Lotfi

farhad@hosseinzadeh.ir

Hamid Sharafi

Hamid_sharafi2013@yahoo.com

Gholamreza Jahanshahloo

jahanshahloo@khu.ac.ir

Mohsen Rostamy-malkhalifeh

mohsen_rostamy@yahoo.com

Mehdi Soltanifar

soltanifar@khayam.ut.ac.ir

Somayeh Razipour-GhalehJough

Somayeh_razipour@yahoo.com

1 Department of Mathematics, Science and Research Branch, Islamic Azad University, Tehran, Iran

2 Department of Mathematics, Semnan Branch, Islamic Azad University, Semnan, Iran indicates that ranking is sensitive to the form of weight constraints, while the second lies in the fact that, since the model is based on the optimistic policy of the selection of weights, it fails to rank the candidates in order, in many circumstances. Hence, in the preference voting process, various methods for ranking candidates were introduced in accordance with Cook and Kress [1]. Green et al. [5] utilized the cross-efficiency method to specify the winning candidates. Wu et al. [6] rendered an iterative algorithm, based on cross-efficiency and the game theory in order to rank the candidates. Similarly, Hashimoto [7] offered a method on the fundamentals of super-efficiency for the ranking of candidates. Noguchi et al. [8] debated on strong ordering in the constraints and rendered an algorithm with multiranking criterions for the ranking of candidates. Obata and Ishii [9] introduced a model based on the use of normalized weights to distinguish between the efficient candidates, whereas, next, Foroughi et al. [10,11] developed the Obata and Ishii method for the inefficient candidate and proposed an algorithm to reduce the computational complexities of this method. Llamazares et al. [12] utilized Green's cumulative conception to determine the winning candidate without solving a model. Wang et al. [13] presented a method for ranking, on the basis of a pessimistic policy in the selection of weights. Subsequently, Wang et al. [14] developed the 
method by defining the virtual deficient candidates. Hosseinzadeh et al. [15] demonstrated that these methods do not qualify for ranking purposes under all circumstances. Soltanifar [16] calculated the minimum efficiency of each candidate by using the optimistic policy. Khodabakhshi et al. [17] introduced an interval based on the optimistic and pessimistic views and then ranked the candidates using the introduced intervals and Llamazares [18] elaborated on the method. Gong et al. [19] utilized DEA models for ranking in preferential voting with uncertain votes. Llamazares [20] also presented a model for ranking candidates through convex sequences of variable weights and ranked the candidates without solving model. Moreover, Izadikhah et al. [21] calculated preference scores of candidates based on different sets of weights. For further studies in connection with the preference ranking, reference should be made to Oukil [22] and Amin et al. [23].

At times, voters may be superior in comparison with each other and the importance of their views is at a level of inequality. Let us take an organization into consideration, where decisions and plans are to be adopted for the future of this institution; and here it calls for and wishes to take advantage of the opinions of all the individuals concerned, ranging from the manager to the officers and employees; but the significance of the views of these persons is not on an equal standing. It is certain that the views of the executives of the company hold more authority, due to experience and responsibility in light of the background, profile and details of the organization's programs, in respect to the opinions of the varied employees who are not eminent. Therefore, in addition to considering the opinions of all the individuals, unequal levels of opinions of voters should also be reflected upon, in group decision-making. Ebrahimnejad [24] presented a model for ranking candidates in a preferential voting for voters with unequal levels. Likewise, Ebrahimnejad et al. [25] proposed a model for a group consensus with a voter's priority principled on the Cook-Kress [1] and extended it to other preferential voting models. In relevance to other researches, which have been performed in this respect, Soltanifar [26] can be indicated to.

In order to utilize their savings and reserves, instead of holding them in banks, people and organizations can invest their assets in the stock exchange and/or participate in the ownership of large manufacturing and commercial or business units. Capacities, to swiftly convert the sum invested into cash and monetization, in comparison with other investments, are the benefits of investing in the stock exchange. Thence, an acquaintance with the stock exchange and its activities can prove to be extremely effective in the economic life of people, as petrochemicals are concerned to be a part of science and technology, which encompasses and is responsible for a survey of the production of chemical materials from oil and gas. Weak or poor performance of some of the petrochemical companies, which are affiliations of the stock exchange and securities, leads to the lack of an optimum use of the available resources and an unsuitable utilization or returns in these units. Thereby, it is absolutely essential to assess the petrochemical companies for ranking purposes and to determine the stance of these companies amidst parallel units. This ranking assists people and organizations to invest their reserves and savings in the stock exchange with a better understanding and recognition in relative to petrochemical companies.

This paper presents a method to rank the petrochemical companies in the Tehran Stock Exchange (TSE), on the basis of preferential voting with voters of unequal voting power level. In this method, initially, candidates in each of the groups are evaluated and then, by utilizing the DEA method and the assurance region, the candidates are ranked. In circumstances, where the number of votes of two candidates is equivalent in the two groups, this method can distinguish between these two candidates, whereas the previous methods do not have this specialty. The incapability of prior models to differentiate between two candidates with an equal number of votes in the two groups of voters is illustrated by a numerical example.

The preliminary voting preferences and data envelopment analysis (DEA) are presented in the second section of the paper, and the proposed method is given in the third section. In the fourth section, first, the proposed method is compared with the previous ones by a numerical example and then the petrochemical companies are ranked utilizing the proposed method. The results are discussed in the fifth section.

\section{Basic concepts}

In this section, preference voting and preferential voting methods with unequal voting power have been described, after which the common set of weights (CSW) model in the data envelopment analysis has been introduced.

\section{Preference voting background}

Preferential voting is a mode to aggregate votes based on the priority of voters. Assuming that $v_{r j}$ represents the number of votes of priority $r(r=1, \ldots, k)$ for the candidate $j(j=1, \ldots, n)$, the overall desirability index for each candidate is defined as follows:

$Z_{j}=\sum_{r=1}^{k} w_{r} v_{r j}, \quad w_{1}>w_{2}>\cdots>w_{k}$.

(ODI, overall desirability index)

where $w_{r}$ signifies the importance of the priority $r$ and the higher value of the above-mentioned denotes a better rank 
for the candidate. Cook and Kress [1] utilized the optimistic policy and determined multipliers $w_{r}(r=1, \ldots, k)$ in such a manner that the overall desirability index for each candidate is the maximum. The model rendered by them is as hereunder:

$$
\begin{aligned}
& Z_{p}(\varepsilon)=\operatorname{Max} \sum_{r=1}^{k} w_{r} v_{r p} \\
& \text { s.t. } \quad \sum_{r=1}^{k} w_{r} v_{r j} \leq 1 \quad j=1, \ldots, n \quad \text { (a) } \\
& w_{r}-w_{r+1} \geq d(r, \varepsilon) \quad r=1, \ldots, k-1 \text { (b) } \\
& w_{k} \geq d(k, \varepsilon)
\end{aligned}
$$

In the above-mentioned model, $d(r, \varepsilon)$ called the discrimination intensity function is nonnegative and $\varepsilon$ is known as the discriminating factor. Each candidate selects the best weight vector for its voting place, and at optimality, at least one of the constraints in (1.a) holds equality. Thereby, each candidate evaluated by model (1) has a value of 1 as its objective function is considered efficient. It could be possible that several candidates be efficient simultaneously, which is expressed as ties in ranking, so model (1) cannot always provide an ordering ranking.

\section{Ranking of candidates in preference voting with unequal voting power}

Assume that there are $t$ groups of voters. The voters in each group select $k$ candidates from among $\mathrm{n}$ candidates present $(k \leq n)$ and prioritize them based on their personal preferences. $w_{r}(r=1, \ldots, s)$ is the weight of $r$ th priority. Similarly, each group of voters is of importance of $u_{h}(h=1, \ldots, t)$. Let us assume that $v_{r j}^{h}$ is the vote of candidate $j$ of priority $r$ in group $h$ of the voters. Ebrahimnejad [24] initially introduced the overall desirability index in the following form:

$Z_{p}=\sum_{h=1}^{t} u_{h}\left(\sum_{r=1}^{s} v_{r p}^{h}\right)+\sum_{r=1}^{s} w_{r}\left(\sum_{h=1}^{t} v_{r p}^{h}\right), \quad p=1, \ldots, n$.

The second term of the above index is identical to the one defined by Cook and Kress [1].

Moreover, $\sum_{r=1}^{s} v_{r p}^{h}$ signifies the number of entire votes that have been rendered to the $p$ candidates by the group $h$. $\sum_{h=1}^{t} v_{r p}^{h}$ signifies the number of entire votes that have been rendered to the $p$ candidates of priority $r$. In utilizing the Cook-Kress [1], Ebrahimnejad [24] proposed the following model:

$$
\begin{array}{llr}
Z_{p}^{*}=\max & \sum_{h=1}^{t} u_{h}\left(\sum_{r=1}^{s} v_{r p}^{h}\right)+\sum_{r=1}^{s} w_{r}\left(\sum_{h=1}^{s} v_{r p}^{h}\right) & \\
\text { s.t. } & & \sum_{h=1}^{t} u_{h}\left(\sum_{r=1}^{s} v_{r j}^{h}\right)+\sum_{r=1}^{s} w_{r}\left(\sum_{h=1}^{s} v_{r j}^{h}\right) \leq 1, j=1, \ldots, n \\
& u_{i}-u_{i+1} \geq \bar{d}(i, \varepsilon), & \\
& w_{r}-w_{r+1} \geq \overline{\bar{d}}(r, \varepsilon), \ldots, t-1 \\
& u_{t} \geq \bar{d}(t, \varepsilon), & \\
& w_{s} \geq \overline{\bar{d}}(s, \varepsilon) . &
\end{array}
$$

In the above-mentioned model, $\bar{d}(i, \varepsilon)$ and $\overline{\bar{d}}(r, \varepsilon)$ are the discriminating intensity functions. Model (2) is solved once for each candidate.

Remark 1 If the number of votes for two candidates in all the groups of voters is equal, model (2) cannot have an effect on the priorities of the voting groups, in relevance to ranking, because the objective function of model (2) only utilizes the sum of votes in each group and does not take into consideration the number of votes of the varied preferences for each group.

In actual fact, according to Remark (1), model (2), in a comparison between the two candidates of equal votes in each group, shows no difference with model (1). In which case, ranking shall only be performed by preference voting and the unequal voting power of the voting groups shall not be included.

Subsequently, Ebrahimnejad et al. [25] employed the DEA approach for group-ranking, along with voters of unequal voting power and introduced the overall desirability index for each candidate in the following manner:

$z_{p}=\sum_{h=1}^{t}\left(u_{h} \sum_{r=1}^{s} w_{r} v_{r p}^{h}\right), \quad p=1, \ldots, n$.

It is evident that if the weights of the various groups of voters are equal, that is, $u_{h}=1, h=1, \ldots, t$, then the overall desirability index of the above-mentioned equates to the overall desirability index of Cook and Kress [1]. Consequently, they utilized the strong ordering of Nogouchi as a discriminating intensity function for the weight vectors of $u=\left(u_{1}, \ldots, u_{t}\right)$ and $w=\left(w_{1}, \ldots, w_{k}\right)$ as follows:

$u_{1} \geq 2 u_{2} \geq \cdots \geq t u_{t}, \quad u_{t} \geq \varepsilon_{1}^{\prime}$

$w_{1} \geq 2 w_{2} \geq \cdots \geq k w_{s}, \quad w_{s} \geq \varepsilon_{2}^{\prime}$

Therefore, the following nonlinear programming model is attained for the evaluation of candidate $p$ :

$$
\begin{aligned}
Z_{p}^{*}= & \max \sum_{h=1}^{t} \sum_{r=1}^{s} w_{r} u_{h} v_{r p}^{h} \\
& \text { s.t. } \quad \sum_{h=1}^{t} \sum_{r=1}^{s} w_{r} u_{h} v_{r j}^{h} \leq 1, \quad j=1, \ldots, n \\
& u_{1} \geq 2 u_{2} \geq \cdots \geq t u_{t}, u_{t} \geq \varepsilon_{1}^{\prime}, \\
& w_{1} \geq 2 w_{2} \geq \cdots \geq k w_{s}, w_{s} \geq \varepsilon_{2}^{\prime} .
\end{aligned}
$$

By transformation $m_{r h}=w_{r} u_{h}$, model (3) is linearized as hereunder: 


$$
\begin{aligned}
Z_{p}^{*}= & \max \sum_{h=1}^{t} \sum_{r=1}^{k} m_{r h} v_{r p}^{h} \\
& \text { s.t. } \quad \sum_{h=1}^{t} \sum_{r=1}^{k} m_{r h} v_{r j}^{h} \leq 1, \quad j=1, \ldots, n \\
& m_{r 1} \geq 2 m_{r 2} \geq \cdots \geq t m_{r t}, m_{r t} \geq \varepsilon, \quad r=1, \ldots, s \\
& m_{1 h} \geq 2 m_{2 h} \geq \cdots \geq k m_{s h}, m_{s h} \geq \varepsilon, \quad h=1, \ldots, t .
\end{aligned}
$$

Similar to the Nogouchi [8], $\varepsilon$ can be obtained as follows: $\varepsilon=\min \{2 / L t(t+1), 2 / L s(s+1)\}$, which $L$ is the total number of voters.

There is also a possibility that model (4) presents more than one candidate with the optimal score of 1 . Hence, Ebrahimnejad et al. [25] have generalized the model (4) in accordance with preference voting ranking methods. In relative to other methods, Soltanifar [26] can be indicated to, who introduced the following model for the ranking of candidates:

$$
\begin{array}{lll}
\max & \frac{\sum_{r=1}^{s} w_{r} y_{r p}}{\sum_{h=1}^{t} u_{i}\left(L-x_{i p}^{\prime \prime}\right)} & \\
\text { s.t. } & \frac{\sum_{r=1}^{s} w_{r} y_{r j}}{\sum_{h=1}^{t} u_{i}\left(L-x_{i j}^{\prime \prime}\right)} \leq 1, & \\
& u_{i}-u_{i+1} \geq \bar{d}(i, \varepsilon), & h=1, \ldots, n, \\
& w_{r}-w_{r+1} \geq \overline{\bar{d}}(r, \varepsilon), & r=1, \ldots, s-1, \\
& w_{s} \geq \overline{\bar{d}}(s, \varepsilon), u_{t} \geq \bar{d}(t, \varepsilon) . &
\end{array}
$$

where $y_{r j}=\sum_{h=1}^{t} v_{r j}^{h}, x_{h j}^{\prime \prime}=\sum_{r=1}^{s} v_{r j}^{h}$ and $L$ is the total number of voters. $y_{r j}$ equates to the total number of votes which candidate $j$ has gained in priority $r$ and $x_{h j}^{\prime \prime}$ is equivalent to the total number of votes which group $h$ has given candidate $j$.

Remark 2 In model (5), if two candidates have the same number of votes in each group, the objective function of model (5) cannot have an effect on the priorities of the voting groups, in relevance to ranking. This in fact conserves conditions for ranking in the form of preference voting, and the level of unequal voting power of the groups is not taken into consideration.

\section{Common set of weights in DEA}

DEA is a mathematical programming approach for evaluating the relative efficiency of homogenous decision-making units (DMUs), as introduced by Charnes et al. [4]. The basic DEA models divide the DMUs into two categories, the 'efficient and inefficient groups,' and likewise, this technique classifies the inefficient decision-making units in terms of their efficiency score, but they are not able to rank the efficient DMUs. Therefore, several methods have been introduced for ranking efficient DMUs. Hosseinzadeh et al. [27] have reviewed the ranking methods in the data envelopment analysis.

Initially, the conventional DEA model which has been introduced by Charnes et al. [4] has been briefly outlined. Assuming that there are $n$ DMUs $(j=1, \ldots, n)$ present, each of them utilizes $x_{i j}(i=1, \ldots, m)$ as inputs and produces $y_{r j}(r=1, \ldots, s)$ as outputs.

The radial efficiency of $\operatorname{DMU}_{p}(p=1, \ldots, n)$ in the input orientation, considering the constant returns to scale assumption, can be achieved by solving the following model:

$$
\begin{array}{ll}
\max & \sum_{r=1}^{s} u_{r} y_{r p} \\
\mathrm{s.t.} & \sum_{r=1}^{s} v_{i} x_{i p}=1, \\
& \sum_{r=1}^{s=1} u_{r} y_{r j}-\sum_{r=1}^{s} v_{i} x_{i j} \leq 0, \quad j=1, \ldots, n, \text { (b) } \\
& u_{r} \geq \varepsilon,(r=1, \ldots, s) ; v_{i} \geq \varepsilon(i=1, \ldots, m) .
\end{array}
$$

That $v_{i}$ and $u_{r}$ are, respectively, the dual coefficients allotted to the $i$ th input and $r$ th output constraints. $\varepsilon$ is a small non-Archimedean number. At optimality, if $\sum_{r=1}^{s} u_{r}^{*} y_{r p}=1$, then $\mathrm{DMU}_{p}$ is known as efficient, in the case that it is not so, it is denoted as being inefficient. Model (6) is solved in segregate for each DMU, and the weights for each DMU are computed optimistically. Thereby, the efficiency of each DMU is obtained with a different set of weights from that of the rest of the DMUs.

In model (1), considering each candidate as a DMU and the votes of each candidate as an output vector together with a fixed input equal to 1 , model (6) along with the weight constraints is equivalent to model (1).

In order to maximize the efficiency to the topmost possible score, DEA models sometimes assign extremely large or very small values to the multipliers. This type of weight assignment cannot be logically justified at times. One of the ways proposed, to overcome this weakness, is to utilize common set of weights. In CSW models, DMUs have less flexibility in weight selection, so as to achieve maximum efficiency. Model (7) is a multi-objective programming problem, which maximizes the efficiency of all the DMUs simultaneously.

$$
\begin{aligned}
& \max \left\{\frac{\sum_{r=1}^{s} u_{r} y_{r 1}}{\sum_{i=1}^{m} v_{i} x_{i 1}}, \ldots, \frac{\sum_{r=1}^{s} u_{r} y_{r n}}{\sum_{i=1}^{m} v_{i} x_{i n}}\right\} \\
& \text { s.t. } \frac{\sum_{r=1}^{s} u_{r} y_{r j}}{\sum_{i=1}^{m} v_{i} x_{i j}} \leq 1, \quad j=1, \ldots, n, \\
& u_{r} \geq 0, \quad r=1, \ldots, s \\
& v_{i} \geq 0, \quad i=1, \ldots, m \text {. }
\end{aligned}
$$

There are several diverse methods for solving model (7); refer to Steuer [28]. One of the methods is the use of goal programming (GP). In this method, the ideal level for each objective function is requested from the decision-maker (DM) and it is considered as the goal. Subsequently, the minimal amount of deviation from the goals is calculated. Since the efficiency value equivalent to 1 is desirable in 
DEA technique, the goal of all objective functions is considered to be equal to 1 (Hosseinzadeh et al. [29]).

Liu et al. [30] presented the following model for evaluating with a common set of weights.

$$
\begin{aligned}
& \min \sum_{j=1}^{n}\left(\Delta_{j}^{-}+\Delta_{j}^{+}\right) \\
& \text {s.t. } \frac{\sum_{r=1}^{s} u_{r} y_{r j}+\Delta_{j}^{+}}{\sum_{i=1}^{m} v_{i} x_{i j}-\Delta_{j}^{-}}=1, \quad j=1, \ldots, n, \\
& u_{r} \geq \varepsilon, \quad r=1, \ldots, s, \\
& v_{i} \geq \varepsilon, \quad i=1, \ldots, m, \\
& \Delta_{j}^{+}, \Delta_{j}^{-} \geq 0, \quad j=1, \ldots, n \text {. }
\end{aligned}
$$

Here, $\Delta_{j}^{-}$and $\Delta_{j}^{+}$are deviation variables of the $j$ th goal. The linear form of model (8) is as follows:

$$
\begin{array}{lll}
\min & \sum_{j=1}^{n} \varphi_{j} & \\
& \text { s.t. } & \sum_{r=1}^{s} u_{r} y_{r j}-\sum_{i=1}^{m} v_{i} x_{i j}+\varphi_{j}=1, j=1, \ldots, n, \\
& u_{r} \geq \varepsilon, & r=1, \ldots, s, \\
& v_{i} \geq \varepsilon, & i=1, \ldots, m, \\
& \varphi_{j} \geq 0, & j=1, \ldots, n .
\end{array}
$$

Model (9) is a linear programming problem that evaluates DMUs using a common set of weights.

Definition 1 After solving model (9), at optimality if $\varphi_{j}^{*}=0$ then $\mathrm{DMU}_{j}$ is efficient.

\section{Proposed method}

The utilization of voting and particularly so, in relevance to preference voting in group decision-making, is important from this viewpoint that staff or those from the lower strata of organizations can voice their opinions without fear of the consequences, even if these opinions are against the outlooks of the managerial levels. The voting of voters with unequal level offers the scope for experts, to have a greater influence in decision-making. In this section, a method for selecting the 'winner' candidate in preference voting of unequal voting power has been proposed on the basis of the following procedure.

Step 1 All the candidates, with due attention to the votes obtained from the group $h(h=1, \ldots, t)$ and using Model (10), are assessed. In other words, candidates are separately evaluated by each set of voter groups.

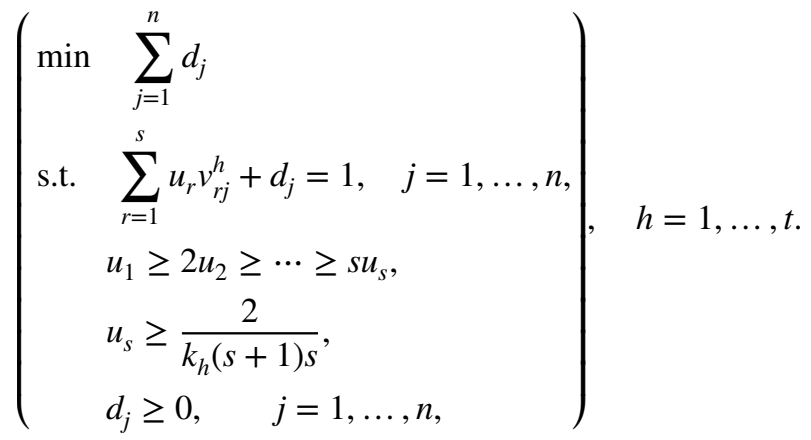

Here, $k_{h}$ signifies the number of voters in group $h$ and $u_{r}$ denotes the importance of the priority $r$ in the voting. If $u_{r}^{*} ; r=1, \ldots, s$ denotes the optimal solution of model (10), then $Z_{j}^{h}=\sum_{r=1}^{s} u_{r}^{*} v_{r j}^{h}$ express the score of candidate $j$, considering the votes of group $h$.

In this step, model (10) is solved $t$ times.

Step 2 In relevance to the preceding step, for each candidate $j$, one vector $\left(Z_{j}^{1}, \ldots, Z_{j}^{t}\right)$ is gained and its components illustrate the overall desirability index of group $h(h=1, \ldots, t)$ for the $j$ th candidate. The higher the value of $Z_{j}^{h}$, the candidate is of greater value, from the viewpoint of group $h$ of the voters. Let $W_{j}^{h}=k_{h} Z_{j}^{h}(h=1, \ldots, t ; j=1, \ldots, n)$. In this manner, the weight of candidate $j$ of group $h$ by utilizing the number of voters of that group is scaled and is denoted as $W_{j}^{h}$. However much, this amount proves to be of magnitude, candidate $j$ holds a superior importance in group $h$.

Step 3 Each candidate is considered as a DMU, the vector $\left(W_{j}^{1}, \ldots, W_{j}^{t}\right)$ signifies the output vector and this is considered alongside 1 as fixed input. Utilizing the common set of weights, the candidates are evaluated by model (11).

The views of the first group of voters are of importance, in relative to that of the second group of voters, and in this manner the second group in relevance to the third group and so on till termination. Let us assume that $\lambda_{h}(h=1, \ldots, t)$ denotes the importance of group $h$ of the voters. We then impose the weight constraint $\lambda_{1} \geq 2 \lambda_{2} \geq \cdots \geq t \lambda_{t}, \lambda_{t} \geq \varepsilon$ on the model below:

$$
\begin{array}{ll}
\min & \sum_{j=1}^{n}\left(t_{j}+t_{j}^{\prime}\right) \\
& \\
\text { s.t. } & \frac{\sum_{h=1}^{t} \lambda_{h} w_{j}^{h}+t_{j}}{\mu-t_{j}^{\prime}}=1, \quad j=1, \ldots, n, \\
& \lambda_{1} \geq 2 \lambda_{2} \geq \cdots \geq t \lambda_{t}, \\
& \lambda_{t} \geq \varepsilon, \mu \geq \varepsilon \\
& t_{j}, t_{j}^{\prime} \geq 0,(j=1, \ldots, n) .
\end{array}
$$


where $\mu$ and $\lambda$, respectively, have relative importance as to the input and output and $\varepsilon$ is a small non-Archimedean numeral. Model (11) is identical to the model of Liu et al. [30] together with imposed weight restrictions. Moreover, in DEA models with constant returns to scale, it is possible to place one of the variables as being equivalent to 1 . Since, in this step, each candidate has one constant input which is equivalent to 1 , the input can be omitted and model (11) converts to the following model:

$$
\begin{aligned}
& \min \sum_{j=1}^{n} t_{j} \\
& \text { s.t. } \quad \sum_{h=1}^{t} \lambda_{i} w_{j}^{h}+t_{j}=0, \quad j=1, \ldots, n, \\
& \lambda_{1} \geq 2 \lambda_{2} \geq \cdots \geq t \lambda_{t}, \\
& \lambda_{t} \geq \varepsilon \\
& t_{j} \geq 0, \quad j=1, \ldots, n \text {. }
\end{aligned}
$$

Let $\left(\lambda^{*}, t^{*}\right)$ denote the optimal solution of model (12). Then, the candidates are ranked by index $\gamma_{j}=\sum_{h=1}^{t} \lambda_{h}^{*} w_{j}^{h}$. The higher the value of $\gamma_{j}$, the candidate $j$ gains a better rank.

The proposed method utilizes the preference voting for ranking candidates in each group of voters. The significance of each candidate in each group is considered as an output vector, and in applying model (12), which is based on the CSW and DEA technique, the candidates are ranked. DEA techniques provide more flexibility in preference ranking. In utilizing model (10), the importance of each candidate in each group can be surveyed in segregate.

\section{Illustrative examples}

In this section primarily, by quoting a numerical example in the particular case, results of the previous models and the proposed method have been compared. Then, the proposed method is illustrated by applying it to rank 10 of the petrochemical companies in the Tehran Stock Exchange.

\section{Numerical example}

In order to select the topmost student, two groups of voters, comprising 26 professors and 26 associate professors, granted the students a priority ranking. This is illustrated in Table 1.

In accordance with the results attained in solving model (11), the score obtained for each $j$ th student in $h$ th group (in other words, $\left.W_{j}^{h}\right)$ is demonstrated in Table 2 .

Given that, the vote of a professor supersedes the vote of an associate professor; hence, $v_{1} \geq v_{2}$ is taken as an assumption, wherein $v_{1}$ and $v_{2}$ denote the importance of the votes of the professors and associate professors, respectively. The values attained for each student from Table 2 are considered as an output vector along with weight constraints, and the proposed model (12) is utilized for evaluation. Table 3 illustrates the results of the proposed method and other methods available for voting on an unequal voting power.

As can be noted, the second row of Table 3 renders the results attained from the proposed method. In the mentioned table, it can be observed that the method of Ebrahimnejad [24] and Ebrahimnejad et al. [25], including the method relative to Soltanifar [26], is unable to discriminate between the Students (1) and (2). Likewise, due to the structural formation of the overall desirability index, as has been mentioned in Remarks 1 and 2, the methods pertaining to Ebrahimnejad [24] and Soltanifar [26] cannot discriminate between Students (3) and (4). However, the proposed method has been able to distinguish between these candidates.

\section{Empirical example}

By utilizing the proposed method, in this section, 10 petrochemical companies which are affiliates of the stock exchange of the TSE are ranked, with due attention to their monetary performance. Based on the views of experts, eight financial indexes for the evaluation of these companies are as follows [31]:

Table 2 Values of $W_{j}^{h}$ for the $j$ th students in group $h$, in relevance to the amounts obtained from model (10)

\begin{tabular}{lllll}
\hline $\begin{array}{l}\text { Final score from each } \\
\text { group }\end{array}$ & Student 1 & Student 2 & Student 3 & Student 4 \\
\hline Professors & 26 & 26 & 14.44 & 11.56 \\
Associate professors & 23.11 & 23.11 & 11.56 & 14.44 \\
\hline
\end{tabular}

Table 1 Number of votes in two levels of priorities for four students, in two groups of voters with varied levels of significance

\begin{tabular}{llcccc}
\hline Group & Priority & Student 1 & Student 2 & Student 3 & Student 4 \\
\hline \multirow{2}{*}{26 professors } & Votes in the 1st priority & 10 & 7 & 6 & 3 \\
& Votes in the 2nd priority & 7 & 10 & 3 & 6 \\
\multirow{2}{*}{26 associate professors } & Votes in the 1st priority & 7 & 10 & 3 & 6 \\
& Votes in the 2nd priority & 10 & 7 & 6 & 3 \\
\hline
\end{tabular}


Table 3 A comparison of the results of the proposed method and other available voting methods with unequal voting power

\begin{tabular}{lllll}
\hline & Student 1 & Student 2 & Student 3 & Student 4 \\
\hline Proposed method & 1.0000 & 0.9615 & 0.5384 & 0.5000 \\
Ebrahimnejad [24] & 1.0000 & 1.0000 & 0.5294 & 0.5294 \\
Soltanifar [26] & 1.0000 & 1.0000 & 0.4309 & 0.4309 \\
Ebrahimnejad et al. & 1.0000 & 1.0000 & 0.5995 & 0.5291 \\
$\quad$ [25] & & & & \\
\hline
\end{tabular}

The current assets, non-current assets, current liabilities, non-current liabilities and capital are inputs, and taxes, allocable profits (losses) and profits (losses) of each share after tax deduction are output factors.

Table 4 demonstrates the inputs and outputs of 10 petrochemical companies in the stock exchange of the TSE. The last column illustrates the CCR efficiency score of each company and is observed that companies 1, 2, 3, 4, 7 and 8 prove to be efficient.

In the data envelopment analysis technique, there are numerous methods available, to rank the efficient DMUs. Hosseinzadeh et al. [27] reviewed some of the models. In utilizing each of the ranking models, different ranks were attained for the decision-making units. The ranking models (RM) discussed by Hosseinzadeh et al. [27] are as follows:

\begin{tabular}{|c|c|c|}
\hline $\begin{array}{l}\text { R.M.1: Andersen } \\
\text { et al. [32] }\end{array}$ & R.M.6: Tone [37] & $\begin{array}{l}\text { R.M.11: Jahanshahloo } \\
\text { et al. [41] }\end{array}$ \\
\hline $\begin{array}{l}\text { R.M.2: Mehrabian } \\
\text { et al. [33] }\end{array}$ & $\begin{array}{l}\text { R.M.7: Sueyoshi } \\
\text { [38] }\end{array}$ & $\begin{array}{l}\text { R.M.12: Rezai Balf } \\
\text { et al. [42] }\end{array}$ \\
\hline $\begin{array}{l}\text { R.M.3: Jahanshahloo } \\
\text { et al. [34] }\end{array}$ & $\begin{array}{l}\text { R.M.8: Sexton et al. } \\
\text { [39] }\end{array}$ & $\begin{array}{l}\text { R.M.13: Ashrafi et al. } \\
\text { [43] }\end{array}$ \\
\hline $\begin{array}{l}\text { R.M.4: Jahanshahloo } \\
\text { et al. [35] }\end{array}$ & $\begin{array}{l}\text { R.M.9: Liu et al. } \\
\text { [30] }\end{array}$ & $\begin{array}{l}\text { R.M.14: Amirteimoori } \\
\text { et al. [44] }\end{array}$ \\
\hline $\begin{array}{l}\text { R.M.5: Jahanshahloo } \\
\text { et al. [36] }\end{array}$ & $\begin{array}{l}\text { R.M.10: Wang et al. } \\
\text { [40] }\end{array}$ & $\begin{array}{l}\text { R.M.15: Chen et al. } \\
\text { [45] }\end{array}$ \\
\hline
\end{tabular}

Ranking the efficient petrochemical companies 1, 2, 3, 4, 7 and 8 by the above-mentioned models, the results are displayed in Table 5. For example, Column (3) demonstrates the fact that DMU2 has ranked first for eleven times and similarly has ranked third once, as well as ranked second thrice.

Hosseinzadeh et al. [27] defined seven properties for ranking models. These properties are as follows:

P1: feasibility; P2: ranking extreme efficient units; P3: complexity in computation; P4: instability; P5: absence of multiple optimal solution; P6: dependency to $\theta$ and slack; and P7: dependency to the number of efficient and inefficient units.

Table 6 shows the properties of the ranking models debated by Hosseinzadeh et al. [27], for 15 various ranking models.

It should be stated that, if the drawbacks of ranking models are slighter, the model carries added importance. The ranking models are placed in many groups of voters. The R.M.2 and R.M.3, each of which has six of the above-mentioned properties, are classed in one group. Models which have five of the listed properties, namely R.M.4, R.M.5 and R.M.8, are encompassed in the second category. In this manner, the third group which is comprised of ranking models illustrating four properties that are R.M.6, R.M.7, R.M.9, R.M.10, R.M.11, R.M.12, R.M.13 and R.M.15 are within group three, whereas the fourth and the fifth groups consist of R.M.1 and R.M.14, respectively.

Considering each ranking model as a 'voter' and every efficient petrochemical company as a 'candidate,' Table 7 illustrates the number of votes based on the various groups of voters. For example, on the basis of the results of the varied ranking models denoted in Table 5, the fifth column of Table 7 demonstrates that the second company has 1 vote in the first priority and 1 vote in the second priority of the first group, 2 votes in the first priority and 1 vote in the second priority of the second group, 7 votes in the first priority, 1 vote in the third priority from the third group and 1 vote in the first priority of the fourth group of voters, including 1 vote in the first priority of the fifth group. Likewise, the other columns in Table 7 designate the number of votes of
Table 4 Inputs and outputs of petrochemical companies

\begin{tabular}{llllllllll}
\hline Company & I1 & I2 & I3 & I4 & I5 & O1 & O2 & O3 & CCR efficiency \\
\hline 1 & 0.084 & 0.249 & 0.067 & 0.267 & 0.424 & 0.189 & 0.209 & 0.149 & 1.00 \\
2 & 0.176 & 0.113 & 0.073 & 0.009 & 0.185 & 0.311 & 0.851 & 0.294 & 1.00 \\
3 & 0.084 & 1.00 & 0.361 & 1.00 & 0.613 & 0.221 & 0.161 & 0.189 & 1.00 \\
4 & 0.233 & 0.785 & 0.426 & 0.643 & 0.467 & 0.326 & 0.513 & 0.492 & 1.00 \\
5 & 0.15 & 0.045 & 0.262 & 0.028 & 0.072 & 0.065 & 0.161 & 0.019 & 0.52 \\
6 & 1.00 & 0.702 & 1.00 & 0.075 & 1.00 & 1.00 & 0.216 & 1.00 & 0.62 \\
7 & 0.206 & 0.11 & 0.145 & 0.005 & 0.228 & 0.367 & 0.75 & 0.288 & 1.00 \\
8 & 0.213 & 0.166 & 0.148 & 0.073 & 0.24 & 0.448 & 1.00 & 0.413 & 1.00 \\
9 & 0.231 & 0.267 & 0.279 & 0.073 & 0.288 & 0.317 & 0.589 & 0.311 & 0.70 \\
10 & 0.038 & 0.092 & 0.033 & 0.001 & 0.437 & 0.027 & 0.009 & 0.007 & 0.40 \\
\hline
\end{tabular}


Table 5 Results attained from the ranking of six efficient 15 different ranking models petrochemical companies with

\begin{tabular}{lllllll}
\hline Ranking model & DMU1 & DMU2 & DMU3 & DMU4 & DMU7 & DMU8 \\
\hline R.M.1 & 6 & 1 & 3 & 5 & 2 & 4 \\
R.M.2 & 6 & 1 & 4 & 5 & 3 & 2 \\
R.M.3 & 6 & 2 & 3 & 4 & 5 & 1 \\
R.M.4 & 6 & 2 & 4 & 5 & 1 & 3 \\
R.M.5 & 6 & 1 & 4 & 5 & 3 & 2 \\
R.M.6 & 6 & 1 & 4 & 5 & 2 & 3 \\
R.M.7 & 4 & 1 & 6 & 5 & 2 & 3 \\
R.M.8 & 4 & 1 & 6 & 5 & 3 & 2 \\
R.M.9 & 4 & 1 & 6 & 5 & 3 & 2 \\
R.M.10 & 5 & 3 & 1 & 2 & 4 & 6 \\
R.M.11 & 6 & 1 & 4 & 5 & 3 & 2 \\
R.M.12 & 6 & 1 & 4 & 5 & 3 & 2 \\
R.M.13 & 6 & 1 & 4 & 5 & 2 & 3 \\
R.M.14 & 3 & 2 & 6 & 4 & 1 & 5 \\
R.M.15 & 6 & 1 & 4 & 5 & 2 & 3 \\
\hline
\end{tabular}

Table 6 Properties of ranking model quoted by Hosseinzadeh et al. [27]

\begin{tabular}{llllllll}
\hline & P1 & P2 & P3 & P4 & P5 & P6 & P7 \\
\hline R.M.1 & - & - & $\checkmark$ & - & $\checkmark$ & $\checkmark$ & - \\
R.M.2 & $\checkmark$ & - & $\checkmark$ & $\checkmark$ & $\checkmark$ & $\checkmark$ & $\checkmark$ \\
R.M.3 & $\checkmark$ & - & $\checkmark$ & $\checkmark$ & $\checkmark$ & $\checkmark$ & $\checkmark$ \\
R.M.4 & $\checkmark$ & - & - & $\checkmark$ & $\checkmark$ & $\checkmark$ & $\checkmark$ \\
R.M.5 & $\checkmark$ & - & $\checkmark$ & $\checkmark$ & $\checkmark$ & - & $\checkmark$ \\
R.M.6 & $\checkmark$ & - & - & $\checkmark$ & $\checkmark$ & - & $\checkmark$ \\
R.M.7 & $\checkmark$ & - & - & $\checkmark$ & $\checkmark$ & - & $\checkmark$ \\
R.M.8 & $\checkmark$ & - & - & $\checkmark$ & $\checkmark$ & $\checkmark$ & $\checkmark$ \\
R.M.9 & $\checkmark$ & $\checkmark$ & $\checkmark$ & $\checkmark$ & - & - & - \\
R.M.10 & $\checkmark$ & $\checkmark$ & $\checkmark$ & $\checkmark$ & - & - & - \\
R.M.11 & $\checkmark$ & - & $\checkmark$ & $\checkmark$ & $\checkmark$ & - & - \\
R.M.12 & $\checkmark$ & - & $\checkmark$ & $\checkmark$ & - & - & $\checkmark$ \\
R.M.13 & $\checkmark$ & - & - & $\checkmark$ & $\checkmark$ & - & $\checkmark$ \\
R.M.14 & $\checkmark$ & - & - & - & - & $\checkmark$ & - \\
R.M.15 & $\checkmark$ & - & - & $\checkmark$ & $\checkmark$ & - & $\checkmark$ \\
\hline & & & & & & &
\end{tabular}

each of the petrochemical companies of the five groups of voters.

A ranking model which has the most properties shows ranking results, which are of higher preference. Hence, the first group of votes outstand the votes of the second group and the votes of the second group are superior to that of the third group. Furthermore, it is in this manner that the third group is exceptional to the fourth group and the fourth excels to that of the fifth group. Thence, we have a preference voting system with voters of a level of unequal power. This encompasses six candidates and 15 voters in five groups, with votes of different significant levels. So, by utilizing the proposed method, stated in the third section of this paper, the candidates (efficient petrochemical companies) are ranked with the views of the 15 voters at five different levels of importance. In this manner, by contemplating on the views of all the voters, or in other words, in considering all the ranking models, the efficient petrochemical companies are ranked.

Hence, in order to rank the efficient petrochemical companies, the proposed algorithm is used for preference voting with unequal power that is demonstrated in Table 7. Initially, by using model (10), the relative importance of each candidate in every group of voters is determined and its results are shown in Table 8.

Finally, index $\gamma$ has been computed for each of the efficient petrochemical companies, the results of which are rendered in Table 9. The higher the value of $\gamma$, the candidate shall gain a better ranking. Applying the proposed algorithm, 
Table 7 Number of votes based on the various groups of voters

\begin{tabular}{|c|c|c|c|c|c|c|c|c|}
\hline Group & Members of group & Priority & DMU1 & DMU2 & DMU3 & DMU4 & DMU7 & DMU8 \\
\hline \multirow[t]{6}{*}{ First group } & \multirow{6}{*}{$\begin{array}{l}\text { R.M.2 } \\
\text { R.M.3 }\end{array}$} & 1st priority & 0 & 1 & 0 & 0 & 0 & 1 \\
\hline & & 2nd priority & 0 & 1 & 0 & 0 & 0 & 1 \\
\hline & & 3rd priority & 0 & 0 & 1 & 0 & 1 & 0 \\
\hline & & 4th priority & 0 & 0 & 1 & 1 & 0 & 0 \\
\hline & & 5th priority & 0 & 0 & 0 & 1 & 1 & 0 \\
\hline & & 6th priority & 2 & 0 & 0 & 0 & 0 & 0 \\
\hline \multirow[t]{6}{*}{ Second group } & \multirow{6}{*}{$\begin{array}{l}\text { R.M.4 } \\
\text { R.M.5 } \\
\text { R.M.8 }\end{array}$} & 1st priority & 0 & 2 & 0 & 0 & 1 & 0 \\
\hline & & 2nd priority & 0 & 1 & 0 & 0 & 0 & 2 \\
\hline & & 3rd priority & 0 & 0 & 0 & 0 & 2 & 1 \\
\hline & & 4th priority & 1 & 0 & 2 & 0 & 0 & 0 \\
\hline & & 5th priority & 0 & 0 & 0 & 3 & 0 & 0 \\
\hline & & 6th priority & 2 & 0 & 1 & 0 & 0 & 0 \\
\hline \multirow[t]{6}{*}{ Third group } & \multirow{6}{*}{$\begin{array}{l}\text { R.M.6 } \\
\text { R.M.7 } \\
\text { R.M.9 } \\
\text { R.M.10 } \\
\text { R.M.11 } \\
\text { R.M.12 } \\
\text { R.M.13 } \\
\text { R.M.15 }\end{array}$} & 1st priority & 0 & 7 & 1 & 0 & 0 & 0 \\
\hline & & 2nd priority & 0 & 0 & 0 & 4 & 4 & 3 \\
\hline & & 3rd priority & 0 & 1 & 0 & 0 & 3 & 4 \\
\hline & & 4th priority & 2 & 0 & 5 & 0 & 1 & 0 \\
\hline & & 5th priority & 1 & 0 & 0 & 7 & 0 & 0 \\
\hline & & 6th priority & 5 & 0 & 2 & 0 & 0 & 1 \\
\hline \multirow[t]{6}{*}{ Fourth group } & \multirow[t]{6}{*}{ R.M.1 } & 1st priority & 0 & 1 & 0 & 0 & 0 & 0 \\
\hline & & 2nd priority & 0 & 0 & 0 & 0 & 1 & 0 \\
\hline & & 3rd priority & 0 & 0 & 1 & 0 & 0 & 0 \\
\hline & & 4th priority & 0 & 0 & 0 & 0 & 0 & 1 \\
\hline & & 5th priority & 0 & 0 & 0 & 1 & 0 & 0 \\
\hline & & 6th priority & 1 & 0 & 0 & 0 & 0 & 0 \\
\hline \multirow[t]{6}{*}{ Fifth group } & \multirow[t]{6}{*}{ R.M.14 } & 1st priority & 0 & 1 & 0 & 0 & 0 & 0 \\
\hline & & 2 nd priority & 0 & 0 & 0 & 0 & 1 & 0 \\
\hline & & 3rd priority & 0 & 0 & 1 & 0 & 0 & 0 \\
\hline & & 4th priority & 0 & 0 & 0 & 0 & 0 & 1 \\
\hline & & 5th priority & 0 & 0 & 0 & 1 & 0 & 0 \\
\hline & & 6th priority & 1 & 0 & 0 & 0 & 0 & 0 \\
\hline
\end{tabular}

the last row of Table 9 shows the ranks of the efficient petrochemical companies 1, 2, 3, 4, 7 and 8 .

According to Table 8, DMU2 has the highest score in groups 1 to 4, and as can be observed in Table 9, DMU2 ranked first. DMU1 has the lowest score in groups 1-4 and rated sixth in the ranking with the proposed method in Table 9.
In the first group, DMU7 scored 0.36, whereas DMU8 has gained 1.00. However, in groups 2-5 DMU7 has scored more than DMU8. Since the score of the first group is of priority in view of the second to the fifth groups, including the fact that there is an immense amount of difference in score between these two DMUs in the first group, DMU8 has secured a better ranking than DMU7.
Table 8 Importance of candidates in each group

\begin{tabular}{llllllll}
\hline Group of voters & $\begin{array}{l}\text { Number of voters } \\
\text { in each group }\end{array}$ & DMU1 & DMU2 & DMU3 & DMU4 & DMU7 & DMU8 \\
\hline First group & 2 & 0.22 & 1.00 & 0.39 & 0.30 & 0.36 & 1.00 \\
Second group & 3 & 0.23 & 1.00 & 0.27 & 0.24 & 0.67 & 0.53 \\
Third group & 8 & 0.21 & 1.00 & 0.35 & 0.26 & 0.44 & 0.41 \\
Fourth group & 1 & 0.17 & 1.00 & 0.33 & 0.20 & 0.50 & 0.25 \\
Fifth group & 1 & 0.33 & 0.50 & 0.01 & 0.25 & 1.00 & 0.20 \\
\hline
\end{tabular}


Table 9 Results of ranking with the proposed method

\begin{tabular}{lllllll}
\hline & DMU1 & DMU2 & DMU3 & DMU4 & DMU7 & DMU8 \\
\hline$\gamma$ & 0.223 & 1.000 & 0.359 & 0.282 & 0.434 & 0.779 \\
Rank & 6 & 1 & 4 & 5 & 3 & 2 \\
\hline
\end{tabular}

In utilizing the proposed algorithm, the entire companies were ranked. As can be observed, none of the companies are in uniform or equate in rank. In relevance to other methods, the proposed algorithm has additional discrimination power; as in ranking, the opinions of voters, as well as the importance of their views, in various categories, are taken under consideration.

\section{Conclusion}

The utilization of preference voting and preferential voting with voters of unequal voting power proves to be extremely fruitful in group decision-making. In this paper, a procedure has been rendered, in order to perform ranking, in the presence of voters of unequal voting power. This is accomplished by using the DEA technique and basic models of preferential voting. Utilizing the DEA method in the proposed algorithm initiates a higher flexibility in analyzing the candidates. Similarly, employing a method of a common set of weights shall provide a more justified weighting to voting priorities. This method is comprised of a power to offer a better discrimination between the candidates in comparison with the methods of Ebrahimnejad [24] and Soltanifar [26], and the supremacy of the method rendered in relevance to the prior methods has been illustrated with a numerical example. Finally, the proposed method has been utilized as a method to discriminate between 10 petrochemical companies in the Tehran Stock Exchange.

Open Access This article is distributed under the terms of the Creative Commons Attribution 4.0 International License (http://creativeco mmons.org/licenses/by/4.0/), which permits unrestricted use, distribution, and reproduction in any medium, provided you give appropriate credit to the original author(s) and the source, provide a link to the Creative Commons license, and indicate if changes were made.

\section{References}

1. Cook, W.D., Kress, M.: A data envelopment model for aggregating preference rankings. Informs 36(11), 1302-1310 (1990)

2. Thompson, R., Jr, Singleton F.D., Thrall, R.M., Smith, B.A.: Comparative site evaluations for locating a high-energy physics lab in Texas. Interfaces 16(6), 35-49 (1986)

3. Thompson, R., Glangemeiar, L. N., Lee, C. T., Thrall, R. M.: The measurement of productive efficiency with an application to Kansas Royland wheat farming, Jesse H. Jones Graduate School of Administration Working Paper, 65 (1989)
4. Charnes, A., Cooper, W.W., Rhodes, E.: Measuring the efficiency of decision making units. Eur. J. Oper. Res. 2(6), 429444 (1978)

5. Green, R.H., Doyle, J.R., Cook, W.D.: Preference voting and project ranking using DEA and cross evaluation. Eur. J. Oper. Res. 90, 461-472 (1996)

6. Wu, J., Liang, L., Zha, Y.: Preference voting and ranking using DEA game cross efficiency model. J. Oper. Res. Soc. Japan 52(2), 105-111 (2009)

7. Hashimoto, A.: A ranked voting system using a DEA/AR exclusion model: a note. Eur. J. Oper. Res. 97, 600-604 (1997)

8. Noguchi, H., Ogawa, M., Ishii, H.: The appropriate total ranking method using DEA for multiple categorized purposes. J. Comput. Appl. Math. 146, 155-166 (2002)

9. Obata, T., Ishii, H.: A method for discriminating efficient candidates with ranked voting data. Eur. J. Oper. Res. 151, 233-237 (2003)

10. Foroughi, A.A., Tamiz, M.: An effective total ranking model for a ranked voting system. Omega 33, 491-496 (2005)

11. Foroughi, A.A., Jones, D.F., Tamiz, M.: A selection method for a preferential election. Appl. Math. Comput. 1631, 07-116 (2005)

12. Llamazares, B., Pena, T.: Preference aggregation and DEA: an analysis of the methods proposed to discriminate efficient candidates. Eur. J. Oper. Res. 197, 714-721 (2009)

13. Wang, Y.M., Chin, K.S.: Discriminating DEA efficient candidates by considering their least relative total scores. J. Comput. Appl. Math. 221, 106-113 (2007)

14. Wang, N.S., Yi, R.H., Liu, D.: A solution method to the problem proposed by Wang in voting systems. J. Comput. Appl. Math. 221, 106-113 (2008)

15. Hosseinzadeh Lotfi, F., Fallahnejad, R.: A note on "A solution method to the problem proposed by wang in voting systems". Appl. Math. Sci. 5(62), 3051-3055 (2011)

16. Soltanifar, M.: Introducing an interval efficiency for each candidate in ranked voting data using data envelopment analysis. Int. J. Soc. Syst. Sci 3(4), 346-361 (2011)

17. Khodabakhshi, M., Aryavash, K.: Aggregating preference rankings using an optimistic pessimistic approach. Comput. Ind. Eng. 85, 13-16 (2015)

18. Llamazares, B.: Aggregating preference rankings using an optimistic-pessimistic approach: closed-form expressions. Comput. Ind. Eng. 110, 109-113 (2017)

19. Gong, Z., Zhang, N., Li, K., Martinez, L., Zhao, W.: Consensus decision models for preferential voting with abstentions. Comput. Ind. Eng. 115, 670-682 (2018)

20. Llamazares, B.: Ranking candidates through convex sequences of variable weights. Group Decis. Negot. 25(3), 567-584 (2016)

21. Izadikhah, M., Farzipoor Saen, R.: Solving voting system by data envelopment analysis for assessing sustainability of suppliers. Group Decis. Negot. (2019). https://doi.org/10.1007/s 1072 6-019-09616-7

22. Oukil, A.: Exploiting value system multiplicity and preference voting for robust ranking. Omega (2019). https://doi.org/10.1016/j. omega.2019.03.006

23. Amin, G.R., El-Bouri, A.: A minimax linear programming model for dispatching rule selection. Comput. Ind. Eng. 121, 27-35 (2018) 
24. Ebrahimnejad, A.: A new approach for ranking of candidates in voting systems. Opsearch 49(2), 103-115 (2012)

25. Ebrahimnejad, A., Tavana, M., Santos-Arteaga, F.J.: An integrated data envelopment analysis and simulation method for group consensus ranking. Math. Comput. Simul. 119, 1-17 (2015)

26. Soltanifar, M.: A new voting model for groups with members of unequal power and proficiency. Int. J. Ind. Math. (IJIM). Accepted (Scientific)

27. Hosseinzadeh, L.F., Jahanshahloo, G.R., Khodabakhshi, M., Rostamy-Malkhlifeh, M., Moghaddas, Z., Vaez-Ghasemi, M.: A review of ranking models in data envelopment analysis. J. Appl. Math. 2013, 492421 (2013)

28. Steuer, R.E.: Multiple criteria optimization: theory, computation, and application. Wiley, New York (1986)

29. Hosseinzadeh Lotfi, F., Jahanshahloo, G.R., Memariani, A.: A method for finding common set of weights by multiple objective programming in data envelopment analysis. South West J. Pure Appl. Math. 1, 44-54 (2000)

30. Liu, F.F., Peng, H.H.: Ranking of units on the DEA frontier with common weights. Comput. Oper. Res. 35(5), 1624-1637 (2008)

31. Codal.ir [homepage on the Internet]. Tehran: securities and exchange organization; 2008-18. http://www.codal.ir. Accessed Feb 2018

32. Andersen, P., Petersen, N.C.: A procedure for ranking efficient units in data envelopment analysis. Manag. Sci. 39(10), 12611294 (1993)

33. Mehrabian, S., Alirezaee, M.R., Jahanshahloo, G.R.: A complete efficiency ranking of decision making units in data envelopment analysis. Comput. Optim. Appl. 14(2), 261-266 (1999)

34. Jahanshahloo, G.R., Pourkarimi, L., Zarepisheh, M.: Modified MAJ model for ranking decision making units in data envelopment analysis. Appl. Math. Comput. 174(2), 1054-1059 (2006)

35. Jahanshahloo, G.R., Junior, H.V., Hosseinzadeh Lotfi, F., Akbarian, D.: A new DEA ranking system based on changing the reference set. Eur. J. Oper. Res. 181(1), 331-337 (2007)
36. Li, S., Jahanshahloo, G.R., Khodabakhshi, M.: A super efficiency model for ranking efficient units in data envelopment analysis. Appl. Math. Comput. 184(2), 638-648 (2007)

37. Tone, K.: A slacks-based measure of super-efficiency in data envelopment analysis. Eur. J. Oper. Res. 143(1), 32-41 (2002)

38. Sueyoshi, T.: DEA non-parametric ranking test and index measurement: slack-adjusted DEA and an application to Japanese agriculture cooperatives. Omega 27(3), 315-326 (1999)

39. Sexton, T.R., Silkman, R.H., Hogan, J.: Data envelopment analysis: critique and extensions. In: Silkman, R.H. (ed.) Measuring efficiency: an assessment of data envelopment analysis, pp. 73-105. Jossey-Bass, San Francisco (1986)

40. Wang, Y.-M., Luo, Y., Liang, L.: Ranking decision making units by imposing a minimum weight restriction in the data envelopment analysis. J. Comput. Appl. Math. 223(1), 469-484 (2009)

41. Jahanshahloo, G.R., Hosseinzadeh Lotfi, F., Shoja, N., Tohidi, G., Razavyan, S.: Ranking using $l 1$-norm in data envelopment analysis. Appl. Math. Comput. 153(1), 215-224 (2004)

42. Rezai Balf, F., Zhiani Rezai, H., Jahanshahloo, G.R., Hosseinzadeh Lotfi, F.: Ranking efficient DMUs using the Tchebycheff norm. Appl. Math. Model. 36(1), 46-56 (2012)

43. Ashrafi, A., Jaafar, A.B., Lee, L.S., Bakar, M.R.A.: An enhanced Russell measure of super-efficiency for ranking efficient units in data envelopment analysis. Am. J. Appl. Sci. 8(1), 92-96 (2011)

44. Amirteimoori, A., Jahanshahloo, G.R., Kordrostami, S.: Ranking of decision making units in data envelopment analysis: a distancebased approach. Appl. Math. Comput. 171(1), 122-135 (2005)

45. Chen, J.-X., Deng, M., Gingras, S.: A modified super-efficiency measure based on simultaneous input-output projection in data envelopment analysis. Comput. Oper. Res. 38(2), 496-504 (2011) 